УДК 004.942

\author{
Я. О. Каліновський \\ ${ }^{1}$ Інститут проблем реєстрації інформації НАН України \\ вул. М. Шпака, 2, 03113 Київ, Україна \\ ${ }^{2}$ Національний технічний університет України \\ «Київський політехнічний інститут імені Ігоря Сікорського» \\ Проспект Перемоги, 37, 03113 Київ, Україна
}

\title{
Методика вибору гіперкомплексних числових систем для моделювання цифрових реверсивних фільтрів
}

\begin{abstract}
Розглянуто визначення гіперкомплексного ицифрового фільтра та перетворення його передавальної функиії до вигляду гиперкомплексної функиіі. Запропоновано методику вибору гіперкомплексної числової системи для еквівалентування гіперкомплексного фільтра аналогу в дійсному вигляд $i$.
\end{abstract}

Ключові слова: гіперкомплексна числова система, цифровий фільтр, передавальна функція, норма, спряження, триплексні числа.

\section{Вступ}

Цифровим фільтром називається цифрова система, яка використовується для фільтрації дискретного сигналу. Він може бути реалізований як програмним засобом, так і за допомогою спеціалізованого апаратного забезпечення. В обох випадках цифровий фільтр можна застосовувати для фільтрації, як в реальному часі, так i для попередньо збереженого значення сигналу. В даній роботі розглядаються тільки алгоритми синтезу структури програмного фільтра. Треба зазначити, що на основі цих структур можуть бути реалізовані також і апаратні рішення цифрових фільтрів.

Застосування гіперкомплексних числових систем (ГЧС) для синтезу структур цифрових фільтрів можуть надати суттєві переваги. Як показано в роботах [18], цифрові фільтри з гіперкомплексними параметрами мають більшу швидкодію та кращі характеристики за інтегральною параметричною чутливістю.

Представлення передавальної функції цифрового фільтра 3 дійсними параметрами до передавальної функції з гіперкомплексними параметрами базується на наступних міркуваннях.

() Я. О. Каліновський, Ю. Є. Боярінова 
Нехай є гіперкомплексна числова система $\Gamma(e, m)$ вимірності $m$. Розглянемо відношення двох поліномів з гіперкомплексними коефіцієнтами від оператора зсуву $z=e^{j \omega}$ :

$$
R(z)=\frac{P(z)}{Q(z)}
$$

де поліноми у чисельнику та знаменнику мають вигляд:

$$
P(z)=\sum_{i=0}^{l} p_{i} z^{-i}, Q(z)=\sum_{i=0}^{l} q_{i} z^{-i}, p_{i}, q_{i} \in \Gamma(e, m), q_{0}=1 .
$$

Функція $R(z)$ (1) належить до класу дробово-раціональних функцій, у яких у чисельнику та знаменнику присутні елементи базису $e=\left\{e_{1}, \ldots, e_{m}\right\}$ деякої гіперкомплексної числової системи $\Gamma(e, m)$. Приведемо функцію (1) до вигляду гіперкомплексної функції. Нагадаємо, що гіперкомплексна функція має наступну формy [9]:

$$
f(X)=\sum_{i=1}^{m} f_{i}\left(x_{1}, \ldots, x_{m}\right) \cdot e_{i}, \quad X=\sum_{i=1}^{m} x_{i} e_{i} \in \Gamma, x_{i} \in R
$$

Теоретичною основою такого приведення є алгоритм ділення двох гіперкомплексних чисел, що викладений в [9]. Для його реалізації необхідно чисельник і знаменник виразу (1) помножити на поліном, що спряжений до знаменника.

Нехай спряжений поліном має вигляд [9]:

$$
\overline{Q(z)}=\sum_{i=0}^{l} \bar{q}_{i} z^{-i}
$$

Добуток $Q(z) \cdot \overline{Q(z)}$ є нормою полінома $Q(z)$, що помножений на одиничний елемент $\varepsilon$ системи $\Gamma(e, m)$ :

$$
Q(z) \cdot \overline{Q(z)}=N(Q(z)) \cdot \varepsilon .
$$

Причому $N(Q(z)) \in R$.

Норма гіперкомплексного числа $\epsilon$ форма $m$-го ступеня відносно компонентів цього числа. Так як $Q(z)$ - поліном $l$-го ступеня, то норма $N(Q(z))$ буде формою $(l \cdot m)$-го ступеня відносно оператора $z$.

Відповідно спряжене число $\overline{Q(z)}$ буде формою ступеня $l(m-1)$, добуток $P(z) \cdot \overline{Q(z)}$ буде формою ступеня $m$ відносно елементів гіперкомплексного числа, а відносно оператора $z$ - ступеня $(m \cdot l)$.

Таким чином, функція (1) перетворюється в

$$
R(z)=\frac{P(z) \cdot \overline{Q(z)}}{N(Q(z))},
$$


яку можна представити у вигляді гіперкомплексної функції, так як її знаменник дійсне число:

$$
\frac{P(z) \cdot \overline{Q(z)}}{N(Q(z))}=\sum_{i=1}^{m} \frac{f_{i}(z)}{N(Q(z))} \cdot e_{i}=\sum_{i=1}^{m} R_{i}(z) \cdot e_{i} .
$$

Поліноми, які знаходяться у чисельниках і знаменниках компонент гіперкомплексної функції (5), параметрично залежать від коефіцієнтів поліномів (3).

Так як, відповідно до (2) $q_{0}=1$, то можна представити знаменник (6) у вигляді

$$
N(Q(z))=N^{*}(Q(z))+1
$$

\section{Гіперкомплексна передавальна функція}

Представимо, що (2) - передавальна функція цифрового фільтра, в якому інформація має гіперкомплексну структуру та перетворюється за законами виконання гіперкомплексних операцій. Передавальна функція такого фільтра буде також гіперкомплексною:

$$
R(z)=R_{1}(z) \cdot e_{1}+R_{2}(z) \cdot e_{2}+\ldots+R_{m}(z) \cdot e_{m},
$$

Створюючи по кожній вимірності свій дійсний фільтр. При цьому сигнал на вході має тільки одну ненульову компоненту, але після першої ж операції він перетворюється на повне гіперкомплексне число.

Нехай заданий цифровий фільтр $(l \cdot m)$-го порядку з дійсною передавальною функцією

$$
H=\frac{\sum_{i=0}^{m l} \phi_{i} z^{-i}}{\sum_{i=1}^{m l} \varphi_{i} z^{-i}+1}
$$

Обираючи належним способом для $k \in \overline{1, \ldots, m \cdot l}$ такий набір параметрів поліномів $f_{k}(z)$ і $N^{*}(Q(z))$, що

$$
R_{k}(z)=\frac{f_{k}(z)}{N^{*}(Q(z))+1}=\frac{\sum_{i=0}^{m l} \phi_{i} z^{-i}}{\sum_{i=1}^{m l} \varphi_{i} z^{-i}+1}
$$

та, пропонуючи без обмеження узагальнення $k=1$, ми отримуємо, що фільтр 3 передавальною функцією (9) фільтрує вхідний сигнал по каналу першої розмірності так само, як і фільтр з передавальною функцією (10).

На виході корисним буде сигнал по каналу першої розмірності, але перший фільтр має порядок $l$, а другий $-m \cdot l$. 


\section{Синтез гіперкомплексного фільтра за дійсним оригіналом}

Продемонструємо процес синтезу гіперкомплексного фільтра за його дійсним оригіналом - фільтром третього порядку. Нехай передавальна функція такого фільтра має вигляд

$$
H_{R}=\frac{\varphi_{3} z^{-3}+\varphi_{2} z^{-2}+\varphi_{1} z^{-1}+\varphi_{0}}{\phi_{3} z^{-3}+\phi_{2} z^{-2}+\phi_{1} z^{-1}+1},
$$

де всі коефіцієнти дійсні.

Нехай необхідно синтезувати гіперкомплексний фільтр, що є еквівалентним даному, але порядок якого дорівнює одиниці, тобто передавальна функція (11) прийме вигляд

$$
H_{\Gamma}=\frac{A+B z^{-1}}{\varepsilon+C z^{-1}}
$$

де $A, B$ та $C$ - гіперкомплексні числа, які належать деякій комутативній ГЧС третьої вимірності. Відповідно до (6)

$$
\begin{aligned}
& H_{\Gamma}=\frac{A+B z^{-1}}{\varepsilon+C z^{-1}}=\sum_{i=1}^{3}\left(A+B z^{-1}\right) \overline{\left(\varepsilon+C z^{-1}\right)} / N\left(\varepsilon+C z^{-1}\right)= \\
& =\sum_{i=1}^{3} \alpha_{i}\left(a_{1}, a_{2}, a_{3}, b_{1}, b_{2}, b_{3}, c_{1}, c_{2}, c_{3}, z^{-1}\right) * e_{i} / \beta\left(c_{1}, c_{2}, c_{3}, z^{-1}\right),
\end{aligned}
$$

де $\alpha_{i}\left(a_{1}, a_{2}, a_{3}, b_{1}, b_{2}, b_{3}, c_{1}, c_{2}, c_{3}, z^{-1}\right)$ та $\beta\left(c_{1}, c_{2}, c_{3}, z^{-1}\right)$ - поліноми третього ступеня відносно оператора зсуву $z^{-1}$, а інші змінні будуть параметрами.

Оскільки сигнал буде оброблятися по першому каналу, тобто $i=1$, то передавальна функція по першому каналу буде

$$
H_{\Gamma}^{1}=\frac{\alpha_{1}\left(a_{1}, a_{2}, a_{3}, b_{1}, b_{2}, b_{3}, c_{1}, c_{2}, c_{3}, z^{-1}\right)}{\beta\left(c_{1}, c_{2}, c_{3}, z^{-1}\right)},
$$

а умовою еквівалентності буде можливість такого вибору параметрів $a_{1}, a_{2}, a_{3}, b_{1}, b_{2}, b_{3}, c_{1}, c_{2}, c_{3}$, що

$$
H_{\Gamma}^{1}=H_{r}
$$

Якщо поліноми $\alpha_{1}\left(a_{1}, a_{2}, a_{3}, b_{1}, b_{2}, b_{3}, c_{1}, c_{2}, c_{3}, z^{-1}\right)$ i $\beta\left(c_{1}, c_{2}, c_{3}, z^{-1}\right)$ представити у вигляді

$$
\begin{gathered}
\alpha_{1}\left(a_{1}, a_{2}, a_{3}, b_{1}, b_{2}, b_{3}, c_{1}, c_{2}, c_{3}, z^{-1}\right)=\sum_{j=0}^{3} \alpha_{1}^{j}\left(a_{1}, a_{2}, a_{3}, b_{1}, b_{2}, b_{3}, c_{1}, c_{2}, c_{3}\right) z^{-j}, \\
\beta\left(c_{1}, c_{2}, c_{3}\right)=\sum_{j=1}^{3} \beta^{j}\left(c_{1}, c_{2}, c_{3}\right) z^{-j}
\end{gathered}
$$

то, використовуючи метод невизначених коефіцієнтів, можна рівність (15) перетворити в систему з 7 рівнянь з 9 невідомими: 


$$
\left\{\begin{array}{c}
\alpha_{1}^{j}\left(a_{1}, a_{2}, a_{3}, b_{1}, b_{2}, b_{3}, c_{1}, c_{2}, c_{3}\right)=\phi_{j}, \quad j=0,1,2,3, \\
\beta^{j}\left(c_{1}, c_{2}, c_{3}\right)=\varphi_{j} .
\end{array}\right.
$$

Таким чином, синтез гіперкомплексного фільтра за його дійсним оригіналом зводиться до визначення гіперкомплексних параметрів у виразі (12), компоненти яких є рішеннями системи (16). Але при цьому залишається відкритим питання вибору конкретної ГЧС, за допомогою якої будується система (16).

Необхідною умовою існування дійсних рішень системи (16) є існування дійсних рішень автономної системи з трьох останніх рівнянь системи (16). Звичайно, що існування дійсних рішень цієї системи не гарантує існування дійсних рішень системи (16), але їхня відсутність показує, що ГЧС, в якій був побудований вираз норми, не можна використовувати для синтезу структури фільтра.

Крім того, для вибору ГЧС вагомим є вимога існування ізоморфної ГЧС 3 незаповненою структурою, перехід до якої зменшить кількість дійсних операцій при функціонуванні фільтра.

\section{Аналіз різноманітних ГЧС на придатність їх до синтезу фільтра третього порядку}

Задача синтезу гіперкомплексного фільтру зводиться до вибору відповідної ГЧС третьої вимірності та визначення гіперкомплексних чисел $A, B$ та $C$ так, що (12) еквівалентує фільтр (11) відповідно до (4).

У таблиці показано загальний вигляд норми знаменника передавальної функції (12) усіх можливих комутативних ГЧС розмірності 3, які наведені в роботі [9]. Позначення цих ГЧС також відповідають [9].

Загальний вигляд норм знаменника

передавальної функції для різноманітних ГЧС третього порядку

\begin{tabular}{|c|c|c|}
\hline № & ГЧС & Норма \\
\hline 1 & $G_{31}, G_{32}$ & $1+\frac{3 c_{1}}{z}+\frac{3 c_{1}^{2}}{z^{2}}+\frac{c_{1}^{3}}{z^{3}}$ \\
\hline 2 & $T$ & $\begin{array}{r}1+\frac{3 c_{1}-c_{3}}{z}+\frac{c_{2}^{2}+3 c_{1}^{2}-2 c_{3} c_{1}-c_{3}^{2}}{z^{2}}+ \\
\frac{c_{1} c_{2}^{2}+c_{2}^{2} c_{3}+c_{1}^{3}-c_{3} c_{1}^{2}+c_{3}^{3}-c_{1} c_{3}^{2}}{z^{3}}\end{array}$ \\
\hline 3 & $G_{33}$ & $1+\frac{3 c_{1}}{z}+\frac{3 c_{1}^{2}-3 c_{2} c_{3}}{z^{2}}+\frac{c_{1}^{3}-3 c_{1} c_{2} c_{3}+c_{3}^{3}+c_{2}^{3}}{z^{3}}$ \\
\hline 4 & $3 R$ & $\frac{c_{2} c_{3}}{z^{2}}+\frac{c_{1} c_{2} c_{3}}{z^{3}}$ \\
\hline 5 & $R \oplus W$ & $\frac{c_{2}^{2}-c_{3}^{2}}{z^{2}}+\frac{c_{1}\left(c_{2}^{2}-c_{3}^{2}\right)}{z^{3}}$ \\
\hline 6 & $R \oplus C$ & $\frac{c_{2}^{2}+c_{3}^{2}}{z^{2}}+\frac{c_{1}\left(c_{2}^{2}+c_{3}^{2}\right)}{z^{3}}$ \\
\hline 7 & $R \oplus D u$ & $\frac{c_{2}^{2}}{z^{2}}+\frac{c_{1} c_{2}^{2}}{z^{3}}$ \\
\hline
\end{tabular}


Побудуємо для ГЧС $G_{31}$ систему еквівалентування (9) для коефіцієнтів $c_{1}, c_{2}, c_{3}:$

$$
\left\{\begin{array}{c}
3 c_{1}=\varphi_{1} \\
3 c_{2}=\varphi_{2} \\
c_{1}^{3}=\varphi_{3} .
\end{array}\right.
$$

Ця система в загальному випадку не має рішень, тобто це означає, що ГЧС непридатна для синтезу гіперкомплексного фільтра.

Розглянемо ГЧС $G_{33}$. Для неї ця система приймає вигляд:

$$
\left\{\begin{array}{c}
3 c_{1}=\varphi_{1}, \\
3 c_{1}^{2}-3 c_{2} c_{3}=\varphi_{2}, \\
c_{1}^{3}-3 c_{1} c_{2} c_{3}+c_{2}^{3}+c_{3}^{3}=\varphi_{3} .
\end{array}\right.
$$

А ця система може мати дійсні рішення при відповідних значеннях правих частин рівняння.

Аналіз інших ГЧС третьої вимірності показує, що сформульованим вимогам задовольняє тільки розглянута ГЧС $G_{33}$, а також система триплексних чисел $T$.

Однак систему $G_{33}$ відкидаємо за такою причиною. Як показано в $[1,9]$, системи $T, G_{33}$ та $R \oplus C$ ізоморфні:

$$
T \simeq G_{33} \simeq R \oplus C .
$$

При моделюванні функціонування фільтра для зниження кількості дійсних операцій доцільно зробити ізоморфне перетворення з системи $T$ або $G_{33}$ до ізоморфної ГЧС $R \oplus C$, виконати обчислення та повернутися назад. Але якщо матриця оператора ізоморфізму систем $T$ i $R \oplus C$ має простий вигляд [9]

$$
\left(\begin{array}{ccc}
1 & 1 & 0 \\
0 & 0 & \pm 1 \\
1 & 0 & -1
\end{array}\right),
$$

і не додає дійсних множень, то оператор ізоморфізму систем $G_{33}$ та $R \oplus C$ має більш складний вигляд

$$
\left(\begin{array}{ccc}
1 & 1 & 0 \\
1 & -1 / 2 & -\sqrt{3} / 2 \\
1 & -1 / 2 & \sqrt{3} / 2
\end{array}\right),
$$

тобто, при ізоморфному перетворенні з $G_{33}$ до $R \oplus C$ і назад доведеться компоненти сигналу множити на ірраціональне число, що збільшує кількість множень. 
За викладених вище причин для моделювання гіперкомплексного фільтра доцільно використовувати гіперкомплексну числову систему триплексних чисел $T$.

\section{Висновки}

Показано, що основним методом визначення доцільності використання для синтезу структури гіперкомплексного цифрового фільтра тієї чи іншої ГЧС є аналіз загального вигляду виразу норми знаменника гіперкомплексної передавальної функції фільтра. Цей вираз повинен бути поліномом від оператора зсуву $z^{-1}$, а також включати всі компоненти числа $C$ - множника при операторі зсуву в знаменнику.

Однак ці умови є лише необхідними при синтезі гіперкомплексного фільтра, так як система рівнянь еквівалентування (16) може не мати дійсних роз'язків при виконанні цих умов. У цьому випадку потрібно переходити до іншої ГЧС, якщо $€$ така можливість, або переходити до ГЧС більш високих порядків. Останній шлях потребує подальших досліджень.

На закінчення слід зазначити, що отримання виразу для норм в різних ГЧС вимагає громіздких алгебраїчних перетворень. Вивід таких виразів став можливим завдяки застосуванню створеного авторами даної роботи комплексу гіперкомплексних обчислень [11]. Для оцінки ефективності роботи цього комплексу наведемо приклад виводу виразу норми для знаменника передавальної функції (12) у системі триплексних чисел $T$ :

$$
\begin{gathered}
C:=\left[1+c[1] \cdot z^{-1}, c[2] \cdot z^{-1}, c[3] \cdot z^{-1}, c[4] \cdot z^{-1}\right] \\
\text { collect (expand }(\text { factor }(\operatorname{Norma}(C, \operatorname{SearchHNS}(\mathrm{T}, \operatorname{LibHNS}())))), z) \\
1+\frac{3 c_{1}-c_{3}}{z}+\frac{c_{2}^{2}+3 c_{1}^{2}-2 c_{3} c_{1}-c_{3}^{2}}{z^{2}}+\frac{c_{1} c_{2}^{2}+c_{2}^{2} c_{3}+c_{1}^{3}-c_{3} c_{1}^{2}+c_{3}^{3}-c_{1} c_{3}^{2}}{z^{3}} .
\end{gathered}
$$

Як бачимо тут, крім операторів мови Maple, застосовуються процедури комплексу гіперкомплексних обчислень Norma, SearchHNS ma LibHNS.

1. Калиновский Я.А., Ландэ Д.В., Бояринова Ю.Е., Хицко Я.В. Гиперкомплексние числовые системы и быстрые алгоритми цифровой обработки информации. Киев: ИПРИ НАНУ, 2014. 130 с.

2. Toyoshima H. Computationally Efficient Implementation of Hypercomplex Digital Filters. IEICE Trans. Fundamentals. 2002, Aug. E85-A. 8. P. 1870-1876.

3. Schutte H.D. Digital filter zur Verarbeitung komplexer und hyper komplexer Signale. Dissertation. Paderborn, 1991. 100 p.

4. Schulz D., Seitz J., LustosadaCosta J.P. Widely Linear SIMO Filtering for Hypercomplex Numbers. IEEE Information Theory Workshop. 2011. Р. 390-394.

5. Каліновський Я.О., Федоренко О.В. Основи побудови цифрових фільтрів із гіперкомплексними коефіцієнтами. Реєстрація, зберігання і оброб. даних. 2009. Т. 11. № 1. С. 52-59.

6. Калиновский Я.А., Хицко Я.В. Применение неканонических гиперкомплексних числових систем для оптимизации суммарной параметрической чувствительности реверсивних цифрових фильтров. Реєстрація, зберігання і оброб. даних. 2014. Т. 16. № 4. С. 3-11. 
7. Калиновский Я.А., Бояринова Ю.Е., Хицко Я.В. Оптимизация суммарной параметрической чувствительности реверсивних цифрових фільтров с коэффициентами в неканонических гиперкомплексних числових системах. Электронное моделирование. 2015. Т. 37. № 5. С. 117-126.

8. Kalinovsky Y.A., Boyarinova Y.E., Khitsko Y.V. Reversible Digital Filters Total Parametric Sensitivity Optimization using Non-canonical Hypercomplex Number Systems. http://arxiv.org/abs/ 1506.01701 (Submitted on 25 Jan 2015). P.9.

9. Синьков М.В., Бояринова Ю.Е., Калиновский Я.А. Конечномерные гиперкомплексные числовые системы. Основи теории. Применения. Киев: Инфодрук, 2010. 388 с.

10. Калиновский Я.А., Бояринова Ю.Е., Сукало А.С. Гиперкомплексные числовые системы четвертой размерности. Киев: ИПРИ НАНУ, 2017. 128 с.

11. Kalinovsky Y.A., Boyarinova Y.E., Sukalo A.S., Khitsko Y.V. The basic principles and the structure and algorithmically software of computing by hypercomplex number. arXiv 1708.04021. 2017. P. 12.

Надійшла до редакції 22.02.2019 